\title{
The Techno-Numerate Nurse: Results of a Study Exploring Nursing Student and Nurse Perceptions of Workplace Mathematics and Technology Demands
}

\author{
Daniel H. Jarvis \\ Nipissing University, dhjarvis@sympatico.ca
}

Andrea Kozuskanich

Nipissing University, aakozuskanich589@community.nipissingu.ca

Barbi Law

Nipissing University, barbil@nipissingu.ca

Karey D. McCullough

Nipissing University, kareym@nipissingu.ca

Follow this and additional works at: https://qane-afi.casn.ca/journal

Part of the Curriculum and Instruction Commons, Higher Education Commons, Other Nursing Commons, and the Science and Mathematics Education Commons

\section{Recommended Citation}

Jarvis, Daniel H.; Kozuskanich, Andrea; Law, Barbi; and McCullough, Karey D. (2015) "The Techno-Numerate Nurse: Results of a Study Exploring Nursing Student and Nurse Perceptions of Workplace Mathematics and Technology Demands," Quality Advancement in Nursing Education - Avancées en formation infirmière: Vol. 1: Iss. 2, Article 5. DOI: https://doi.org/10.17483/2368-6669.1024

This Article is brought to you for free and open access by Quality Advancement in Nursing Education - Avancées en formation infirmière. It has been accepted for inclusion in Quality Advancement in Nursing Education - Avancées en formation infirmière by an authorized editor of Quality Advancement in Nursing Education - Avancées en formation infirmière. 


\section{Introduction}

Nurses, the largest of the health care professional groups, spend the most direct time with patients; thus, their role in health outcomes is critical (Canadian Institute for Health Information, n.d.). Furthermore, nursing in the contemporary context has become an increasingly complex and demanding profession (Sulosaari, Suhonen, \& Leino-Kilpi, 2011). According to Sorensen and Yankech (2008), "The professional nursing role has become increasingly sophisticated. Modern health care is complicated by copious nursing knowledge, highly sophisticated technological equipment, and complex health care systems" (p. 208).

At a time when the aging North American demographic is moving into the latter stages of life_-stages that require increased healthcare support at home and in hospital-it comes as no surprise that well-prepared nurses are in high demand across the country (Canadian Immigration News, 2013). The Canadian Nurses Association (2009) predicted that by 2022, there would be a shortage of 60,000 registered nurses in Canada. Canadian society will not only need a very large number of nurses over the next decade, but will also greatly benefit from ensuring that each newly-qualified nurse graduate has the requisite level of numeracy (proficiency with mental and worked arithmetic), technology-based skills (informatics competency and information literacy), and critical thinking (ability to solve problems, often under stressful conditions) that will permit these professionals to provide safe and effective care in hospitals and other healthcare contexts.

\section{Review of the Literature}

Two main areas of the existing literature were reviewed for this study: mathematics for nursing and technology for nursing. Both of these topics will be discussed at length within this article.

\section{Mathematics for Nursing}

One of the current challenges in nursing education is an apparent lack of mathematical literacy skills among nursing students and graduates (Dilles, Vander Stichele, Van Bortel, \& Elseviers, 2011; Grandell-Niemi, Hupli, Leino-Kilpi, \& Puukka, 2003; Huse, 2010). This lack of mathematical literacy has often been included as part of the widespread debates regarding the instances of nurse prescription errors, sometimes resulting in serious patient injury or even death (Baker et al., 2004; Elnour, Ellahham, \& Al Qassas, 2008; Fothergill-Bourbonnais \& Caswell, 2014; Serembus, Wolf, \& Youngblood, 2001). Even within an era of advanced technology, basic mathematical literacy can therefore still be argued to be an essential and critical aspect of nurse education and practice.

Brown (2002) administered a computational mathematics test to more than 850 associate degree nursing students across the USA and found the results to be remarkably consistent, with the mean score being 75\%. More specifically, his findings showed that students were mathematically underprepared, particularly in skills involving fractions, decimals, and percents, the mathematic skills necessary for medication calculation. Beyond a lack of mathematical competence in terms of basic computational skills, there remains an even more pervasive and underlying challenge. For many nursing students, and working nurses, they simply do not possess adequate conceptual understanding in order to know what is actually being required of them for math-related problems (Eastwood, Boyle, Williams, \& Fairhall, 2011; Vagliardo, 2008).

This concern regarding the lack of mathematical competency and confidence among nursing students has led to the introduction, in some jurisdictions (e.g., United Kingdom), of 
mandatory high-stakes drug calculation skills tests which students must pass as part of the culmination of their undergraduate nursing degree or diploma programs (Coben, Hodgen, Hutton, \& Ogston-Tuck, 2008; Wright, 2009). Others have suggested that an admission entry test for undergraduate nursing programs should be instituted that would include a focus on the mathematical competency required for the profession (see, for example, Dray, Perkins, Faller Fritsch, \& Burke, 2010). Still other programs have decided to offer innovative instructional strategies and/or student supports for dosage calculation skills throughout their nursing programs (Galligan, Loch, \& Lawrence, 2010; Greenfield, Whelan, \& Cohn, 2006; Meechan, Mason, \& Catling, 2011; Middleton, 2008).

For example, in some nursing programs, attempts have been made to increase numeracy skills among nursing students through the introduction of computer-based or online mathematical learning software (Hodge, 2002), such as the well-known computer-based dosage calculation program, Authentic World, with mixed results in terms of effectiveness (Ainsworth et al., 2012; Hutton et al., 2010). A concerned group of Canadian nursing instructors from both the collaborative $\mathrm{BScN}$ program at the University of Ontario Institute of Technology and the practical nursing program at Durham College, formed a joint Math Committee to analyze the inadequacies in their nursing students' mathematics abilities and to plan for math competency development. This team, over time, implemented a number of strategies, including a math screening test for Year 1 students, online modules for independent study, routine pre-practicum testing for Year 2-4 students, Medication Math Carts, and group tutoring sessions in basic math and dosage calculation skills organized by invited faculty of education students (Cummings, 2011, pp. 22-24). As stated in Cummings' summary, "By unmasking and addressing a serious knowledge gap, our math committee has been able to come up with strategies that will ultimately improve medication administration safety and mitigate risks to patients" (p. 24). However, the impact of these strategies has yet to be examined.

A number of studies have pointed to the importance of having a consistent mathematical formula teaching method adopted and demonstrated by all faculty within a given nursing program. For example, Jackson and Carlo (2011) examined a comprehensive approach to teaching and evaluating drug dosage calculations, which involved a fundamentals course in which dosage calculation was introduced and taught with a consistent ratio/proportion technique, self-study workbook assignments in Weeks 1-6, and a dosage calculation class in Week 7 that included review of the self-study assignments, and addressed specific questions in preparation for the dosage calculation test. Their "unified teaching and testing approach" (p. 83) was deemed to be effective.

While it is important to ensure that nurses have mastered fundamental mathematics concepts, ethnographic workplace research conducted by Noss, Hoyles, and Pozzi (2002) emphasized the recognition of "situated mathematical knowledge" (p. 227) as distinct from formalized mathematical content found in course curricula, as professional practice shapes their mathematical knowledge. Similarly, Harding, and Petrick (2008) concluded that teaching strategies need to account for the ever-changing complexity of the workplace, and that they should incorporate experiential knowledge. Wright $(2009,2012)$ also argues for the importance of clinical-embedded dosage calculation practice, within authentic contexts.

Mathematical competency is closely linked with technological competency in nursing, as certain skills from the former area (e.g., drug dosage calculations, problem solving) are often 
required within the latter area (Axe, 2011; Hardy, Drury, Frotjold, Brown, \& Crosweller, 2003). We now turn to a more detailed discussion of technology.

\section{Technology for Nursing}

In this section we will discuss two key areas that have become increasingly central in nursing education and practice: "informatics competencies" (Ainsley \& Brown, 2009: Gassert, 2008; Ip, Jones, \& Jacobs, 2007; Spencer, 2012), or the ability of nurses to effectively understand, manipulate, and retain skills across a wide variety of technology-based tools for practice; and "information literacy" (Flood, Gasiewicz, \& Delpier, 2010; Schutt \& Hightower, 2009), or the ability of nurses to be able to effectively access, evaluate, and filter information from the Internet and other print-based resources.

According to a study by Li and Kenward (2006), "only $62.1 \%$ of registered nurse study participants felt that they were adequately prepared by their classroom education to use information technology to enhance patient care" (p. 110). The undergraduate learning experience now often involves the use of an extensive list of technologies such as word processing, spreadsheet, and digital presentation software; statistical analysis software (Epstein, Mina, Gaudet, Singh, \& Gula, 2011); video podcasting (Greenfield, 2011; Johnston, Massa, \& Burne, 2013; Strickland, Gray, \& Hill, 2012); personal response systems (Broussard, 2012; McCurry \& Hunter Revell, 2011); personal digital assistants (PDAs) (Cibulka \& Crane-Wider, 2011; George, Davidson, Serapiglia, Barla, \& Thotakura, 2010; Kuiper, 2010; Zurmehly, 2010); educational gaming (Royse \& Newton, 2007; Skiba, 2009); mobile phone short message service (SMS) (Chuang \& Tsao, 2013); laptops (Rush, 2008); online eLearning (Carter \& Graham, 2012; Condon, 2013; Gerkin, Taylor, \& Weatherby, 2009); simulation/virtual environments (Jeffries, 2005; Tanaka et al., 2010); live video-conferencing (Grady, 2011); and Web 2.0 technologies (Kohtz, Gowda, Stockert, White, \& Kennel, 2012). Why many nurses, despite exposure to these different technologies during their nurse preparation experiences, apparently still feel unprepared for the nursing profession is a question worthy of examination.

Nursing students are being prepared for a work environment that will involve yet another layer of advanced technologies, a list of which might include: mobile, wireless computer units (Lai \& Wu, 2012); electronic patient health record systems (Brooks \& Ericson, 2012; GriffinSobel et al., 2010; Holtz, 2010; Jones \& Donelle, 2011); health information technology (HIT) involving telephone/video delivery (Cady, 2012; Cheeseman, 2012); security systems such as fingerprint scanners (Franscisco, 2010); smart pumps (Herring, Ripley, Farmer, \& St Cyr, 2012); e-Healthcare facilitation (Edirippulige, Smith, Beattie, Davies, \& Wootton, 2007); Automated Dispensing System/Cabinets (ADCs or ADS) for medications (McCannon \& O'Neal, 2003); and digital, web-enabled handheld devices such as smartphones and tablets (Bogossian, Kellett, \& Mason, 2009; Hart, 2012).

The Internet has become an ever-present resource in everyday life and within healthcare settings (Anderson \& Enge, 2012; Bembridge, Levett-Jones, \& Jeong, 2011). Nurses are finding themselves more and more involved in Internet resource searching and in related patient teaching roles (Anderson \& Klemm, 2008). Bond conducted two separate yet similar studies with two different groups of British nursing student cohorts $(2004,2010)$, and found that while students in the second study had significantly better ability to carry out basic technology-based tasks and significantly higher levels of Internet use, their ability to apply these skills to more complex information literacy tasks had not increased. 
Barnard, Nash, and O'Brien (2005) have described the direct link between an evidencebased approach to nursing practice and the ability of nurses to access and assess relevant information, "The amount and complexity of information nurses are expected to manage continues to increase exponentially" (p. 505). Flood et al. (2010) proposed an integrated approach wherein information literacy is systematically incorporated across a B.Sc. in nursing curriculum through clinical applications, assignments that advance students' abilities to locate, evaluate, and use information, and the "fostering of a positive appreciation for information literacy when planning safe, effective patient care" (p. 101).

In light of radical changes in available technologies, some argue that nothing short of a complete rethinking of nurse education curriculum, teaching, and assessment is what is now required in order to stay relevant. According to Booth (2006), "Nursing is at the cusp of a truly revolutionary time in its history with the emergence of electronic health technologies... However, technology itself will not transform healthcare without skilled practitioners who have the informatics background to practice in this new paradigm of client care" (p. 1). While some researchers, such as Hall (2009), still suggest that traditional approaches to nurse teaching (e.g., lecturing and small seminar discussions) do not preclude engagement, innovation, and creativity, the overall sense within the recent literature is that radical change in nursing education is more than likely inevitable (Cross, 2011). Bold initiatives such as Technology Informatics Guiding Education Reform (TIGER)-which involves leaders from nursing practice, education, informatics, professional nursing organizations, government organizations, and industry partners whose common goal is to accelerate the adoption of HIT in nursing-will no doubt become commonplace in $21^{\text {st }}$ century nurse education (Fetter, 2009; Hebda \& Calderone, 2010; McCartney, 2010).

While there clearly exists a need for strong mathematics and technology training within nurse education, there is a lack of information on nursing students' and working nurses' perceptions of how prepared they are for the demands of the profession. Understanding their perceptions of their training may provide key insight into how nurse education can be improved to enhance their ability to cope with the dynamic and complex demands of nursing in today's society. We now turn to the research study, explaining goals and methods.

\section{Statement of Research Questions}

Our research study sought answers to the following two research questions: (1) How do current nursing students' perceptions compare with those of actual working nurses, regarding the mathematics and technology demands involved in nursing?; and, (2) What types of course structures, content, pedagogy, or other recommendations could more effectively prepare nurses for the realities of the workplace, in light of mathematics and technology demands?

\section{Methodology}

With a desire to better understand the continuing realities of nursing education and practice in a Canadian context, particularly with regard to required mathematics competency and technology expectations, we invited a group of $4^{\text {th }}$-year nursing students and a group of practicing nurses to complete several online open-response questions. Following this activity, indepth interviews were conducted with three volunteer participants who had taken part in the online component, each of whom worked in a very different healthcare setting.

Our research study was approved by both the participating University Research Ethics Board and by the participating healthcare facility's Research Ethics Board. Eight student nurses and sixty-eight working nurses agreed to participate and complete the online questionnaire 
component, from which three working nurses volunteered to take part in follow-up interviews. All eight nursing students were female, and of the 68 working nurses, eight were male. Participant ages ranged from 21 to 65, with the average ages of the nursing students and working nurses being 22 years and 36 years, respectively. In terms of years of experience among the working nurses, the average was 11.9 years, with a standard deviation of 11.38 years, and a range of 0-40 years in the field. Participants from both groups were asked to respond to the following two broad questions, using a 5-point Likert scale (i.e., ranging from 1-'strongly disagree' to 5-'strongly agree') response:

- I have been adequately prepared for the mathematical thinking required for the nursing profession (e.g., ratio conversions, percent, measurement, checking answers for reasonableness, general numeracy skills).

- I have been adequately prepared for the technological competencies required for the nursing profession (e.g., use of calculators, use of ADCs, word processing, spreadsheets, hospital equipment)."

For each of the above questions, participants were asked to share, in an open response item question, any other thoughts that they might have about mathematics and technology for nursing. Interviews were then conducted by one of the authors with three volunteer nurses. Similar in nature to the online questions, but allowing the participants to expand more fully on their responses, the interviews focused on the following items: perceptions of mathematical and technology-based skills needed for the nursing profession, recollections of math and technology experiences and observed practices during one's nurse preparation, and recommendations for nurse degree programs in terms of math and technology related thinking and skills. These audio files were transcribed verbatim, and then sent back to the participants for member checking. Data from the online open-response items and the three interview transcripts was analyzed using Thematic Analysis methods (i.e., familiarization with data, generating initial codes, searching for emergent themes among codes, reviewing themes, defining and naming themes, and producing the final report). Emergent themes were identified within the two pre-existing broad categories of Mathematics for Nursing and Technology for Nursing.

\section{Report of Findings}

For nursing students, all online question responses were located in the 3-5 range (neutralstrongly agree). For practicing nurses, ratings were in the 1-5 range (strongly disagree-strongly agree). For both groups, mean ratings fell within the 3-4 (neutral-agree) range for each of the main questions (see Table 1).

Table 1. Nursing students' and nurses' perceptions of preparedness in mathematics and technology.

\begin{tabular}{lcccc}
\hline & \multicolumn{2}{c|}{ Nursing Students $(\mathrm{n}=8)$} & \multicolumn{2}{c}{ Practicing Nurses $(\mathrm{n}=68)$} \\
\hline \hline Perceived Preparedness & $\mathrm{M}$ & $\mathrm{SD}$ & $\mathrm{M}$ & $\mathrm{SD}$ \\
\hline Mathematical Thinking & 3.88 & .64 & 4.06 & .94 \\
\hline $\begin{array}{l}\text { Technological } \\
\text { Competencies }\end{array}$ & 3.88 & .64 & 3.78 & .93 \\
\cline { 2 - 5 } & & & & \\
\hline
\end{tabular}


On average, students rated their preparation as somewhat lower than nurses did for mathematics. The group sizes were too dissimilar to conduct between-group analyses with statistical confidence. However, from visual inspection, it is clear that there were no significant differences between new graduates (nursing students) and experienced graduates (working nurses) in terms of perceived preparation for the mathematics and technology demands within nursing practice.

Due to the overlapping nature of the online open response questions and the interview questions (as explained above), and since there were considerably more participants in the working nurses group (68) than in the nursing students group (8), we decided that the reporting of the following sub-themes did not benefit from separate treatment of these sub-groups by data type (online questions/interviews) or participant (nurse/student) role. In what follows, therefore, we report on the combined findings, according to the two main over-arching themes (math/technology for nursing), and the emergent sub-themes.

\section{Mathematics for Nursing}

Three sub-themes relating to the math for nursing emerged from the open-response question data and the interview transcripts: mathematical skills required for practice, mathrelated admission requirements, and course offerings and instructional strategies.

Mathematical skills required for practice: When asked about the mathematical skills required for nursing, many of the participants responded by emphasizing the fact that much of the mathematics needed for practice is actually based on Grades 5-9 mathematics content, yet requires the lucid application of these skills to more complex formulas, and often under stressful conditions. One working nurse noted, "The mathematical skills required for the nursing profession are founded prior to post-secondary education. Post-secondary education that teaches nursing math skills simply outlines the functions that are required to complete the skills, and refreshes the memory." "Nursing mathematics is sensible, deductive, and pragmatic," another nurse shared, " and Algebra is the most often used, when solving for an unknown variable." More specifically, ratio, unit conversions, and dosage and drip rate calculations seem to be among the most popular mathematical skills that are used regularly in hospital work. "Math and dosage calculation are extremely important in the nurses' role. We are providing patients with medication on a frequent basis, and the competency of each nurse is essential," stated one practicing nurse. Mathematics for nursing is also a function of where in the hospital, or healthcare context, one practices, "It depends where you work. For a medical floor you might not use math as much, but when you're in an intensive or a critical care setting, or if you want to go on and get your masters... math is super important." During an interview, a nurse working in a neo-natal intensive care facility elaborated on the specific math skills required in her daily practice: "There are math skills used every day... We calculate the daily amounts of food that a baby needs based on their weight." Another interviewed nurse, working in acute care, explained the difference between the math needed in various areas:

I think it is relatively basic math. It's very simplistic fractions, addition, and subtraction... It's when you get into critical care and emergency nursing where the calculations become a little bit more complex... more complicated medications, like constant infusions, where you incorporate weights, times, [and/or] smaller doses.

The use of mathematical skills in nursing was also explained as being commonly mediated by the use of technology, with calculators and ADS or ADCs being the most 
commonly mentioned technologies. However, the presence of such technology is not always guaranteed to exist within any given healthcare context. A working nurse noted, "With new technology, I have not had to do any very difficult mathematical equations or conversions-very straightforward. However, I worry about working in any hospital that does not have the technological advances." Even with available technology for calculation purposes, nurses commonly expressed their belief that hand-written skills as well as the ability to mentally check results were both critically essential for the nursing profession.

Mathematics for nursing also was described as involving the use of one's nursing peers as a means of checking one's accuracy, particularly in cases where the calculations were more highrisk in nature. An experienced nurse shared, "I feel general knowledge of mathematics is crucial to nursing. However, you also have... another resource which is another nurse-you always second check with another nurse when calculating." This system of double-checking or cosigning was, in some instances, presented as a required feature of the hospital, and in other situations was more of an optional activity that depended on the nurse's level of confidence with the mathematical calculations.

Program admission requirements: A number of the participants felt that a senior mathematics course in secondary school should be listed as a pre-requisite for the nursing degree program, as this is apparently the case at other universities. One $4^{\text {th }}$-year nursing student noted, "I think that there should be higher requirements for admission into the nursing program related specifically to math. Personally, I helped at least 15 of my fellow students in this area as they were greatly lacking in comprehension of math in general." A working nurse stated:

It is unbelievable that math is not a prerequisite to this degree. Students who are not strong in math in high school [therefore] see this as a relaxed degree... So why bother being good at it? Little do they know that math is an everyday occurrence once you're working.

Several participants from among our sample had completed senior math courses and/or mathematics-related undergraduate programs prior to entering their nursing education, and in these cases, they described feeling more confident about the mathematics that was encountered in the nursing degree program and in nursing practice. One such working nurse noted, for example, "I took advanced mathematics classes in high school and in university prior to beginning my BScN degree, so I feel I was well prepared before entering the program." Another experienced nurse with a previous degree in science/math shared: "I don't find that most nurses have the adequate preparation... I don't feel that I received any mathematical preparation in my nursing degree-just memorizing formulas, instead of teaching students how to understand it." "The BScN program needs to have more dosage calculation teaching," stated another working nurse, "I'm good in the math, however, other students may feel that there was not enough mathematical preparation."

Clearly, whether or not a school of nursing requires applicants to have successfully completed secondary school senior mathematics courses, it behooves them to at least express the importance of mathematical competency for the profession, and to clearly explain the emphasis that will be put on math skills throughout the degree program.

Course offerings and instructional strategies: Many participating nurses in the study clearly supported the idea of introducing a stand-alone 'mathematics for nursing' course in the first year of the nurse education degree program. For example, one practicing nurse noted, "I 
think it would be beneficial for students to have a dosage calculation course, rather than a statistics math course. The majority of nurses will be staff nurses, and they are required to give multiple medications in various ways." Another working nurse explained, "I think that there should be a dosage calculation course offered in the nursing program. We were only given a couple of classes to learn how to complete dosage calculations correctly, which I believe was not enough time." "I think that would be very beneficial," noted a practicing nurse interviewee, "having a first year basic math course that is nursing-related."

A number of participants felt that mathematical formulas, for example, dosage calculations, were not explicitly taught during their undergraduate degree program. One working nurse's comment read, "I would have benefitted from increased teaching regarding dosage calculations during my degree, rather than being expected to teach myself and pass a test each year." During her interview, the neo-natal nurse explained: "We never had a math course-it was part of our clinical practice, and it was an expectation that we would learn it ourselves... [W]e were kind of just given a textbook and told you need to practice and then achieve." Beyond teaching themselves the required mathematics, several participants mentioned having to tutor other students. If strong in mathematics, some, as in the case of the following working nurse, felt that they were required to assume peer-tutoring roles, "My understanding of mathematics came from a previous university degree. Many of my classmates, however, I believe were underprepared, as I found myself explaining and teaching these skills."

If mathematical skills were taught in their program, participants would often describe conflicting methods used by different instructors within different courses. One working nurse reflected, "I feel that there are too many instructors teaching, and that leads to confusion. Having more than one instructor led to many inconsistences in the mathematical requirements and formulas that were provided." Another practicing nurse noted, "Throughout my degree it was difficult having multiple teachers all with their own shortcuts and formulas that were not consistent. I was either trying to teach myself through the Internet or asking my clinical instructor for help."

We now turn to the second broad category, technology for nursing, which, while overlapping with mathematics (e.g., calculators), also provides us with unique issues and insights.

\section{Technology for Nursing}

The three main emergent sub-themes relating to the technology for nursing were: technology-related skills required in the nursing profession, technology addressed in nurse degree programs, and issues surrounding evidence-based practice and Internet access.

Technological skills required for practice. According to several of the more experienced participants who had been working in nursing careers for some time, technology for practice had seen remarkable changes. "There have been a lot of changes and new equipment to learn since I graduated from a 2-year nursing diploma course 31years ago," claimed one such working nurse. Another practicing nurse noted, "Technology has greatly advanced since I graduated 37 years ago. Veteran nurses like myself have had to learn to keep up with the demands of more and more technology in nursing. Wherever I have worked, training has been available." Yet another practicing nurse shared, "In my training 23 years ago, there was little of today's technology, and therefore little focus in this area." 
Ironically, as the presence of new technologies has increased, the need for competency in pencil-and-paper math skills and the mental discipline of being able to check answers/numbers for reasonableness has correspondingly decreased. One working nurse noted, "Earlier in my career, I would need to use mathematics, conversions, and formulas much more often. Now, most of it is done for me by pharmacy and written on electronic Medical Administration Reports." Another experienced nurse participant similarly asserted, "Formulas are often forgotten because the pharmacy does a lot of the math for the dosages." Regardless of the power of new machines, one still needs to be able to check answers/dosages for reasonableness, as expressed by the working nurse participant, "I think we should be trained and equipped for quicker mental math."

If much has changed regarding technology, just what types of technology are now available and used in nursing practice? As expected, working nurses indicated that they commonly use calculators, and software packages such as word processing tools and spreadsheets. Some hospitals were also reported as using computer tracking systems, like Meditech, for patient information and status updates. Computers-on-Wheels (COWs) -mobile carts with desktop or laptop computers that can be moved around a ward and accessed by nurses on shift-were described as being used primarily for patient tracking, often using older DOSbased (as opposed to more recent Windows-based) software. As the interviewed nurse working in mental health noted, "Even the nurses graduating right now, at twenty-two years old, have difficulty with the technology in hospitals that we've got currently. It's really difficult, some programs, like Meditech-they're hard to learn how to navigate."

Depending on one's unit, there can be a wide variety of machines with which a nurse must be familiar. According to several participants, the advent of ADS and ADCs for drug dispersing has brought with it increased accountability and efficiency, along with some more problematic challenges These challenges include congested time cycles-where nurses are all trying to access the ADCs simultaneously, occasional running out of a certain drug within the machine, the incidence of power or system failure and the existence, or not, of back-up plans, and the potential for conflict between pharmacy schedules and patient drug schedules.

The interviews provided further insight into this issue. The mental health nurse noted that pills come already halved, when appropriate, in the machines. "So, that is really nice, eliminating those kinds of calculations. But on the other hand, it also eliminates the thinking we need to do about those calculations." In contrast, the neo-natal intensive care nurse shared that they do not use dispensing systems in her place of work. "But I prefer our method because with the few medications that do get sent up by pharmacy, most people assume that since pharmacy has done it, it must be right, so a lot of people don't check the dose." The acute care nurse reinforces the accountability aspect, which is sometimes lost among nurses using the ADC technology:

It goes through an order entry technician who looks at the orders, and then it's confirmed by a pharmacist. But even still, those are all people, so the potential for human error is still there... To me that is just a very dangerous way of thinking. We are the ones dispensing the medications, we are the ones responsible for administering these medications and various things to people-our name and signature is attached-so we should really be the ones to be able to check it... I think the ADCs take away from your skills, in a sense. 
We now move from the technology and related skills that were reported as being part of the working nurse's everyday realities, to the types of reported technology preparation that were received during nurses' degree programs.

Existing technology and related skills found in nurse education programs: Overall, the majority of nursing students and working nurses noted a general sense of being well-prepared for the technology of the workplace. One working nurse felt there could have been more specific training on certain software/machines, "School gave us a very basic understanding of technology. We left knowing what it was about, but never enough to be comfortable with it. Obviously you learn as you use things." Another practicing nurse stated, "I wish I had more formal training on spreadsheets and Excel. I feel that I was trained on the job instead of being trained in school." Yet another experienced nurse reflected, "Throughout my degree it would have helped for someone to review other hospital equipment and different components of charts/documentation that we don't use that often, or at least make us aware of what we may encounter on each unit."

With specific regard to ADC familiarity, there was a significant range of opinion, likely a function of the access, or lack thereof, to the actual machines within the various programs that nurse participants had experienced. Some participants felt that there could have been more preparation with ADCs in their nursing program. One working nurse noted her misgivings about her ADS education: "I was not properly prepared before coming into the clinical setting on how to use ADS, since practical training on how to use the machines was never offered to me during my nursing school program." However, others felt that they had been well-prepared in this area: "The ADC training was fantastic," claimed a $4^{\text {th }}$-year student. "It was more on-the-job training, rather than being taught how to use ADC machines, etc. in school," stated another experienced nurse.

Some participants felt that one's comfort with technology is often a function of one's age or generation, as evidenced in statements such as this one by a working nurse, "I think the most preparation for using technology is age-dependent. Most young people today are completely comfortable using computers as well as learning a new program or technology." The interviewed neo-natal nurse noted, "I didn't find the technology part too hard just because we've kind of grown up with it, so for us to learn new pieces of technology it's no different, and it's not hard."

The notion that technology is very much a function of the specific healthcare context, in terms of geographical location and specialty focus areas, was commonly expressed by participants in statements such as the following by a working nurse, "So much of the work environment is specific to the infrastructure of the institution in question. Training at the student level prepared me for the process of working with new technology." Another experienced nurse participant explained, "As a city, we have the newer technologies like ADS. But in terms of the entire province, if someone wants to work elsewhere in a more remote location, those technologies may not be available." "The technology used throughout the hospital is different in every section," explained one working nurse, "In a palliative area, for example, there is less technology to learn, and in places like the O.R. there is lots!"

Several experienced nurses mentioned a Nursing Informatics course that they had experienced in their degree program, which included a number of different technology components. This course was described as both a 4th-year course for some, and as part of an online "post-RN Bachelor degree" program for others. "The distance education courses did offer 
a Nursing Informatics course which was helpful and informative. Word processing and spreadsheet development were part of the learning plan," explained a graduate of the latter program. Another graduate of this program noted, "In my post-RN Bachelor degree we also had Nursing Informatics, which was a perfect course to learn about new technology in healthcare."

Evidence-based practice and Internet access: Several participants in our study commented on the Internet access found within their respective hospital units, and their common use of this resource. During her interview, the nurse working in a mental health context noted:

Let's say that you get a new diagnosis, or you're looking for actual information. Someone mentions Gravol's anti-cholinergic effect exacerbated-seeing delusions, and so I want to go look at it. So, I'll jump on the computer and go to Google Scholar and type in 'Gravol' and 'delusions', let's see what I can come up with. But, other nurses, especially older nurses, like, that is so beyond them.

She further explained her perceived sense of demographic differences, "I find that there's a big gap between-some of the older nurses have a real difficult time finding information online, and it can become quite frustrating when you're running to help do computer things for other people."

Nursing students noted that they had password-enabled access to licenced Internet-based journal databases, which allowed them to search out information pertaining to healthcare issues. In contrast, however, very few of our working nurses participants mentioned having access to, or using such information databases. Several working nurses explained that there is research-related information shared with nurses regularly at the local, provincial, and national levels, but that it really comes down to how prepared a busy working nurse is to engage with the information and to try to apply it to practice. Several participants mentioned how certain hospitals subscribe to, or themselves create for nurse use, a form of filtered or synopsized research information, via the Internet, such as the resource $U p$ To Date, which greatly reduces the time needed to search information, as well as increasing one's confidence in the information found. The availability of such concise, pre-filtered information systems can not only affect nursing practice, but can also influence another related issue emerging from the data which we found to be most interesting, that of nurses teaching patients and their families using the Internet. As described by the neonatal nurse during her interview:

Each patient has a computer at their bedside... The hospital has its own website and... I use it a lot for teaching... It is easier because instead of parents saying, "Well, I read this on the internet," and you don't know if it's true or not, this is a trusted hospital website based on research.

Not only are patient room $\mathrm{TVs} /$ monitors used to access Internet content, more and more frequently other commonly owned Internet-enabled devices such as PDAs, smartphones, and tablets are being used as well. The interviewed nurse working in acute care and surgical nursing noted, "I do have a smartphone and I do use it at the bedside quite often... Even a lot of our patients are more apt to ask you to pull it up on their phone." The advantages of being able to quickly find relevant, diagnosis- and treatment-related information, as well as using free programs that allow the nurse to focus on visual forms of the related anatomy, are considerable in terms of patient understanding and emotional state. The same participant further added: 
A lot of times, they've had a surgery and they can't visualize their own anatomy. They're not sure what is going on underneath the skin and you just sort of give them a visual. I use it as a comfort measure, because once they get an idea of what's going on they are usually a little bit less anxious.

Clearly, technology plays an ever-increasing role in the work that nurses do in daily practice. Having reported on our findings within these two broad thematic areas (mathematics and technology for nursing), we now provide a section in which we discuss and interpret the findings accordingly.

\section{Interpretation of the Findings}

The responses to the Likert-scale questions do tentatively suggest that both students and working nurses feel moderately to strongly prepared for the demands of nursing practice in mathematics and technology. The online open-response items, along with the three in-depth interviews, have provided rich data which has allowed us to begin to better understand many of the related issues faced by nurses in their working environments, and has also served to highlight areas for improvement in nursing education as students prepare for the workforce.

Clearly, working nurses acknowledge the fact that mathematical competency is an important part of practice. This fact is held in constant tension with the advent of new technologies such as ADCs, and the move towards drug dosages now being calculated, in large part, by pharmacy and then delivered to nursing units/stations. Even in the midst of these major changes to nursing roles and responsibilities, many participants felt that the ability to accurately perform arithmetical skills such as ratio conversions, drip rates, dosage formulas, etc.-both with pen-and-paper (i.e., by hand) and using available technologies (e.g., calculators)- remains critical insofar as the checking of automated measurements and calculations for reasonableness, which must still be done with confidence in order to avoid mistakes with negative, or potentially tragic, consequences (Fothergill-Bourbonnais \& Caswell, 2014). Since the availability of new technologies, such as ADCs, is not guaranteed in every hospital, or even across hospital units, it remains vital that nursing students receive adequate baseline training in mathematical and technological skills that will enable them to be successful in any kind of potential nursing work environment.

While many of the participants indicated an overall appreciation and contentment with their nursing education, certain perceived areas for improvement were shared. Students and working nurses felt that an increased amount of direct and consistent (i.e., among various faculty) mathematical skill teaching would have been helpful during their preparation. Many, along these lines, indicated a preference for a specific course dedicated to the mathematics of nursing, rather than being subsumed as part of other courses, and avoiding the situation where it was a primarily self-directed experience, or one that required constant help from knowledgeable peers. The possibility of introducing secondary school senior math credit prerequisites was also discussed favourably by several participants, as was the need for more clearly-defined descriptions of the high-stakes math emphasis (i.e., pass/fail) realities within any given nurse preparation program and its prevalence with the nursing profession.

In terms of technology, participants expressed a desire to have an increased amount of hands-on training with a variety of hospital machines (e.g., ADCs, I-V) and software titles (e.g., Meditech, KidsCare). The ability to access research literature within the work environment (e.g., Up to Date), and the encouragement of administration and peers to do so, were both shared as 
important conditions for better achieving an evidence-based approach to practice, as required by the College of Nurses of Ontario (CNO).

Within their Practice Standards (CNO, 2002), there is a clear emphasis by the CNO on an evidence-based approach to nursing. In order for this to occur, nursing students must receive adequate education regarding how to access relevant literature, and how to translate this into practice; working nurses must likewise be given access to current research-based literature, and the encouragement from administration and peers to make this a regular part of their everyday practice. Although the Standards have been in place for over a decade in Ontario, research has shown that implementation of an evidence-based approach to nursing has been difficult for practicing nurses owing to a number of persistent obstacles (Pearson, forthcoming; Stetler, 2003; Stetler, McQueen, Demakis, \& Mittman, 2008), including access and adequate training.

The term "bedside manner" is commonly defined as a doctor's (or nurse's) approach or attitude towards a patient. There is no denying that this skill set is paramount to the overall quality of the relationship between the healthcare provider and the patient. In thinking about the increasingly prominent role of the Internet in nurse-patient interactions, we would like to suggest here a new term, "webside manner," with the following formal definition: The quality of personalized instructional care provided by a healthcare professional to the patient and/or family members, using the Internet as a research and teaching resource.

If it is true that nurses are increasingly being asked, or expected, to share Internet-based research, visualization software, medical trends, etc. with patients and their families using hospital room monitors, PDAs, or other "smart-enabled" devices such as patient phones or tablets - then we suggest that it would behoove nurse education programs to proactively focus on Internet searching and filtering skills, and on strategies for effectively communicating with the patient and/or families in light of these realities.

\section{Conclusions}

While we acknowledge that it is clearly not a simple task to restructure $\mathrm{BScN}$ programs in light of budgets, staffing, facilities, related costs, etc., in what follows, we nonetheless do suggest seven recommendations for possible consideration by nurse education providers.

\section{Mathematics for Nursing}

1. Make senior mathematics course(s) a pre-requisite for program admission, and emphasize in marketing.

2. Introduce a stand-alone math course (online, onsite, or hybrid) in at least the first year of the nursing program.

3. Teach math formulas consistently among faculty, emphasizing conceptual understanding within PBL contexts.

\section{Technology for Nursing}

4. Provide more clinical and/or virtual technology/informatics training (e.g., ADCs, computer charting).

5. Raise awareness around potential over-dependency on technology for calculations (need for critical checking).

6. Emphasize the importance of evidence-based practice and its direct relationship to information literacy skills.

7. Recognize "webside manner" skills in terms of established protocols for nurses' role in patient/family teaching. 


\section{Limitations and Future Research Directions}

One limitation of the study was the relatively small group of student nurses-likely owing in part to the recruitment taking place towards the end of the academic year, compared to practicing nurses, who were more available to participate in the study. Another limitation is that we have a situation where some nurses received their education before certain present-day technologies were developed, while others are more recent graduates who may have been trained directly on the existing technologies, making it difficult for us to compare perceptions among groups.

It would be beneficial to replicate this study with a larger sample size, perhaps involving multiple schools of nursing and healthcare centers from different areas of Ontario, or across Canada. Particularly important would be to interview nursing students, and to understand how their perceptions may change throughout their degree program (e.g., what is the role/importance of preceptorship placements versus classroom theory and labs). The Canadian Nurses Association, a professional organization that regulates the standardization of nursing across Canada, oversees the creation and implementation of the Canadian Registered Nursing Exam (CRNE), which nurse graduates must pass in order to receive their full accreditation. Part of this exam features mathematical content. We would therefore also be curious to know how the mathematical learning acquired in nursing education programs compares with the CRNE math content, and whether or not the schools of nursing are aware of any potential disconnect in this regard. Finally, we would also like to delve more deeply into how nurses who have been working for a number of years manage to keep up (or not) with the rapidly changing advances in technology found within healthcare contexts.

In closing, we trust that this paper will serve to stimulate further research projects in the areas of mathematics for nursing (i.e., computation and conceptual understanding), and technology for nursing (i.e., informatics competencies and information literacy), in order to inform and improve nursing education in Canada. 


\section{References}

Ainsley, B., \& Brown, A. (2009). The impact of informatics on nursing education: A review of the literature. Journal of Continuing Education in Nursing, 40(5), 228-232. doi:10.3928/00220124-20090422-02

Ainsworth, H., Gilchrist, M., Grant, C., Hewitt, C., Ford, S., Petrie, M., Torgerson, C. J., \& Torgerson, D. J. (2012). Computer-based instruction for improving student nurses' general numeracy: Is it effective? Two randomised trials. Educational Studies, 38(2), 151-163. doi:10.1080/03055698.2011.598668

Anderson, A. S., \& Klemm, P. (2008). The internet: Friend or foe when providing patient education? Clinical Journal of Oncology Nursing, 12(1), 55-63. doi:10.1188/08.CJON.55-63

Anderson, L. S., \& Enge, K. J. (2012). Education and information for practicing school nurses: Which technology-supported resources meet their needs? Journal of School Nursing, 28(5), 358-369. doi:10.1177/1059840512443261

Axe, S. (2011). Numeracy and nurse prescribing: Do the standards achieve their aim? Nurse Education in Practice, 11(5), 285-287. http://dx.doi.org/10.1016/j.nepr.2010.11.008

Baker, G. R., Norton, P. G., Flintoft, V., Blais, R., Brown, A., Cox, J., ... Tamblyn, R (2004). The Canadian adverse events study: The incidence of adverse events among hospital patients in Canada. Canadian Medical Association Journal, 170(11), 1678-1686. doi:10.1503/cmaj.1040498

Barnard, A., Nash, R., \& O'Brien, M. (2005). Information literacy: Developing lifelong skills through nursing education. Journal of Nursing Education, 44(11), 505-510.

Bembridge, E., Levett-Jones, T., \& Jeong, S. Y. (2011). The transferability of information and communication technology skills from university to the workplace: A qualitative descriptive study. Nurse Education Today, 31(3), 245-252. http://dx.doi.org/10.1016/j.nedt.2010.10.020

Bogossian, F. E., Kellett, S., \& Mason, B. (2009). The use of tablet PCs to access an electronic portfolio in the clinical setting: A pilot study using undergraduate nursing students. Nurse Education Today, 29(2), 246-253. http://dx.doi.org/10.1016/j.nedt.2008.09.001

Bond, C. S. (2004). Surfing or drowning? Student nurses' Internet skills. Nurse Education Today, 24(3), 169-173.

Bond, C. S. (2010). Surfing or still drowning? Student nurses' Internet skills. Nurse Education Today, 30(5), 485-488. http://dx.doi.org/10.1016/j.nedt.2009.11.005

Booth, R. G. (2006). Educating the future eHealth professional nurse. International Journal of Nursing Education Scholarship, 3(1), 1-12. doi:10.2202/1548-923X.1187

Brooks, C. L., \& Erickson, L. K. (2012). What is the solution for clinical nurse educators and the electronic medical record? Teaching \& Learning in Nursing, 7(4), 129-132. doi:10.1016/j.teln.2012.06.003

Broussard, B. B. (2012). To click or not to click: Learning to teach to the microwave generation. Nurse Education in Practice, 12(1), 3-5. http://dx.doi.org/10.1016/j.nepr.2011.03.013

Brown, D. L. (2002). Does $1+1$ still equal 2? A study of the mathematic competencies of associate degree nursing students. Nurse Educator, 27(3), 132-135.

Cady, R. G. (2012). Measuring the impact of technology on nurse workflow: A mixed methods approach. (Doctoral dissertation). Retrieved from ProQuest Dissertations and Theses database. (UMI No. 3505871) 
Canada Immigration News. (2013, August). Nurses in high demand throughout Canada. Retrieved from http://www.cicnews.com/2013/08/nurses-high-demand-canada082809.html

Canadian Institute for Health Education (n.d.). Nurses. Retrieved from http://www.cihi.ca/CIHIextportal/internet/EN/TabbedContent/spending+and+health+workforce/workforce/nurses/ci hi010673

Canadian Nurses Association. (2009). Tested solutions for eliminating Canada's registered nurse shortage. Report highlights. Retrieved from http://www.cna-aiic.ca/CNA/documents/pdf/publications/RN_Highlights_e.pdf

Carter, L., \& Graham, R. D. (2012). The evolution of online education at a small northern Ontario university: Theory and practice. Journal of Distance Education, 26(2), 1-7.

Cheeseman, S. E. (2012). Information literacy: Using computers to connect practice to evidence. Neonatal Network, 31(4), 253-258.

Chuang, Y., \& Tsao, C. (2013). Enhancing nursing students' medication knowledge: The effect of learning materials delivered by short message service. Computers \& Education, 61, 168-175. doi:10.1016/j.compedu.2012.09.013

Cibulka, N. J., \& Crane-Wider, L. (2011). Introducing personal digital assistants to enhance nursing education in undergraduate and graduate nursing programs. Journal of Nursing Education, 50(2), 115-118. doi: 10.3928/01484834-20101230-07

Coben, D., Hodgen, J., Hutton, M., \& Ogston-Tuck, S. (2008). High stakes: Assessing numeracy for nursing. Adult Learning, 19(3), 38-41. doi:10.1177/104515950801900308

College of Nurses of Ontario. (2002). Practice Standards: Professional standards of care competency review. Toronto, ON: Author.

Condon, B. B. (2013). The present state of presence in technology. Nursing Science Quarterly, 26(1), 24. doi:10.1177/0894318412466738

Cross, B. L. (2011). Developing a relationship with the computer in nursing practice: $A$ grounded theory. (Master's thesis). Retrieved from ProQuest Dissertations and Theses database. (UMI No. MR80337)

Cummings, K. E. (2011). Back to basics: Building math competency in nursing students. Canadian Nurse, 107(7), 22-24.

Dilles, T., Vander Stichele, R. R., Van Bortel, L., \& Elseviers, M. M. (2011). Nursing students' pharmacological knowledge and calculation skills: Ready for practice? Nurse Education Today, 31(5), 499-505. doi:10.1016/j.nedt.2010.08.009

Dray, B., Perkins, A., Faller Fritsch, L., \& Burke, L. (2010). Numeracy competence requirements for admission to undergraduate degree programmes: A case study of a programme to prepare pre-registration nursing student candidates for a numeracy entrance test. Journal of Further and Higher Education, 34(1), 83-96. doi:10.1080/03098770903477128

Eastwood, K. J., Boyle, M. J., Williams, B., \& Fairhall, R. (2011). Numeracy skills of nursing students. Nurse Education Today, 31(8), 815-818. doi:10.1016/j.nedt.2010.12.014

Edirippulige, S., Smith, A. C., Beattie, H., Davies, E., \& Wootton, R. (2007). Pre-registration nurses: An investigation of knowledge, experience and comprehension of e-health. Australian Journal of Advanced Nursing, 25(2), 78-83.

Epstein, I., Mina, E. E. S., Gaudet, J., Singh, M. D., \& Gula, T. (2011). Teaching statistics to undergraduate nursing students: An integrative review to inform our pedagogy. 
International Journal of Nursing Education Scholarship, 8(1), 1-15. doi:10.2202/1548923X.2234

Elnour, A. A., Ellahham, N. H., \& Al Qassas, H. I. (2008). Raising the awareness of inpatient nursing staff about medication errors. Pharmacy World \& Science, 30, 182-190. doi:10.1007/s11096-007-9163-6

Fetter, M. S. (2009). Curriculum strategies to improve baccalaureate nursing information technology outcomes. Journal of Nursing Education, 48(2), 78-85. doi:10.3928/01484834-20090201-06

Flood, L. S, Gasiewicz, N., \& Delpier, T. (2010). Integrating information literacy across a BSN curriculum. Journal of Nursing Education, 49(2), 101-104. doi:10.3928/0148483420091023-01

Fothergill-Bourbonnais, F. \& Caswell, W. (2014). Teaching successful medication administration today: More than just knowing your 'rights'. Nurse Education in Practice, 14(4), 391-395. doi:10.1016/j.nepr.2014.03.003

Francisco, J. R. (2010). Fingerprints in place of passwords: A study of technology adoption in the nursing profession. (Doctoral dissertation). Retrieved from ProQuest Dissertations and Theses database. (UMI No. 3398359)

Galligan, L., Loch, B., \& Lawrence, J. (2010). Building academic numeracy in a first year nursing course using an evaluative model of program development. In D. Coben, \& J. O’Donoghue (Eds.), Adult Mathematics Education: Papers From Topic Study Group 8, ICME 11, 11th International Congress on Mathematical Education. National Centre for Excellence in Mathematics and Science Teaching and Learning (pp. 165-181).

Gassert, C. A. (2008). Technology and informatics competencies. Nursing Clinics of North America, 43(4), 507-521. http://dx.doi.org/10.1016/j.cnur.2008.06.005

George, L. E., Davidson, L. J., Serapiglia, C. P., Barla, S., \& Thotakura, A. (2010). Technology in nursing education: A study of PDA use by students. Journal of Professional Nursing, 26(6), 371-376. doi:10.1016/j.profnurs.2010.08.001

Gerkin, K. L., Taylor, T. H., \& Weatherby, F. M. (2009). The perception of learning and satisfaction of nurses in the online environment. Journal for Nurses in Staff Development, 25(1), E8-E13. doi:10.1097/NND.0b013e318194b6a4

Grady, J. L. (2011). The virtual clinical practicum: An innovative telehealth model for clinical nursing education. Nursing Education Perspectives, 32(3), 189-194. http://dx.doi.org/10.5480/1536-5026-32.3.189

Grandell-Niemi, H., Hupli, M., Leino-Kilpi, H., \& Puukka, P. (2003). Medication calculation skills of nurses in Finland. Journal of Clinical Nursing, 12(4), 519-528. doi:10.1046/j.1365-2702.2003.00742.x

Greenfield, S. (2011). Podcasting: A new tool for student retention? Journal of Nursing Education, 50(2), 112-114. doi:10.3928/01484834-20101230-06

Greenfield, S., Whelan, B., \& Cohn, E. (2006). Use of dimensional analysis to reduce medication errors. Journal of Nursing Education, 45(2), 91-94.

Griffin-Sobel, J., Acee, A., Sharoff, L., Cobus-Kuo, L., Woodstock-Wallace, A., \& Dornbaum, M. (2010). A transdisciplinary approach to faculty development in nursing education technology. Nursing Education Perspectives, 31(1), 41-43. http://dx.doi.org/10.1043/1536-5026-31.1.41

Hall, W. A. (2009). Whither nursing education? Possibilities, panaceas, and problems. Nurse Education Today, 29(3), 268-275. doi:10.1016/j.nedt.2008.09.005 
Harding, L., \& Petrick, T. (2008). Nursing student medication errors: A retrospective review. Journal of Nursing Education, 47(1), 43-47. doi:10.3928/01484834-20080101-05

Hardy, J., Drury, P., Frotjold, A., Brown, P., \& Crosweller, D. (2003). Developing critical thinking skills in undergraduate nurses using information and communication technologies. Nursing Monograph 2003, 6-8.

Hart, C. (2012). Technology and nursing education: Building an online toolkit. The Journal of Continuing Education in Nursing, 43(10), 441-442. doi:10.3928/00220124-20120925-95

Hebda, T., \& Calderone, T. L. (2010). What nurse educators need to know about the TIGER initiative: Technology Informatics Guiding Education Reform. Nurse Educator, 35(2), 56-60. doi:10.1097/NNE.0b013e3181ced83d

Herring, H., Ripley, T., L., Farmer, K., C., \& St Cyr, M. (2012). An intervention to increase safety feature use on smart pumps: A quality improvement initiative. Journal of Pharmacy Technology, 28(3), 119-123. doi:10.1177/875512251202800306

Hodge, J. E. (2002). The effect of math anxiety, math self-efficacy, and computer-assisted instruction on the ability of undergraduate nursing students to calculate drug dosages. (Doctoral dissertation). Retrieved from ProQuest Dissertations and Theses database. (UMI No. 3064590)

Holtz, B. E. (2010). An examination of the adoption of electronic medical records by rural hospital nurses through the unified theory of acceptance and use of technology lens. (Doctoral dissertation). Retrieved from ProQuest Dissertations and Theses database. (UMI No. 815519581).

Huse, J. S. (2010). Comparison of teaching strategies on teaching drug dosage calculation skills in fundamental nursing students. (Doctoral dissertation). Retrieved from ProQuest Dissertations and Theses database. (UMI No. 3404512)

Hutton, M., Coben, D., Hall, C., Rowe, D., Sabin, M., Weeks, K., \& Woolley, N. (2010). Numeracy for nursing, report of a pilot study to compare outcomes of two practical simulation tools - An online medication dosage assessment and practical assessment in the style of objective structured clinical examination. Nurse Education Today, 30(7), 608614. doi:10.1016/j.nedt.2009.12.009

Ip, B., Jones, S., \& Jacobs, G. (2007). Retention and application of information technology skills among nursing and midwifery students. Innovations in Education \& Teaching International, 44(2), 199-210. doi:10.1080/14703290701241018

Jackson, N., V., \& Carlo, J. J. (2011). Problem solved: Dosage calculation in a nursing program. Nurse Educator, 36(2), 80-83. doi:10.1097/NNE.0b013e31820b532b

Jeffries, P. (2005). Technology trends in nursing education: Next steps. Journal of Nursing Education, 44(1), 3-4.

Johnston, A. N. B., Massa, H., \& Burne, T. H. J. (2013). Digital lecture recording: A cautionary tale. Nurse Education in Practice, 13(1), 40-7. doi:10.1016/j.nepr.2012.07.004

Jones, S., \& Donelle, L. (2011). Assessment of electronic health record usability with undergraduate nursing students. International Journal of Nursing Education Scholarship, 8(1), 1-18. doi:10.2202/1548-923X.2123

Kohtz, C., Gowda, C., Stockert, P., White, J., \& Kennel, L. (2012). The use of web 2.0 technologies. Nurse Educator, 37(4), 162-167. doi:10.1097/NNE.0b013e31825a87b3

Kuiper, R. A. (2010). Metacognitive factors that impact student nurse use of point of care technology in clinical settings. International Journal of Nursing Education Scholarship, 7(1), 1-15. doi:10.2202/1548-923X.1866 
Li, S., \& Kenward, K. (2006). A national survey of nursing education and practice of newly licensed nurses. Journal of Nursing Administration's Healthcare, Law, Ethics, and Regulation, 8(4), 110-115.

Lai, C., \& Wu, C. (2012). Supporting nursing students' critical thinking with a mobile web learning environment. Nurse Educator, 37(6), 235-236. doi:10.1097/NNE.0b013e31826f27ee

McCannon, M., \& O’Neal, P. V. (2003). Results of a national survey indicating information technology skills needed by nurses at time of entry into the work force. Journal of Nursing Education, 42(8), 337-340. doi:10.3928/0148-4834-20030801-04

McCartney, P. R. (2010). An educational resource for health information technology. MCN, the American Journal of Maternal Child Nursing, 35(1), 59-60. doi:10.1097/01.NMC.0000366813.05574.c9

McCurry, M. K., \& Hunter Revell, S. M. (2011). Evaluating the effectiveness of personal response system technology on millennial student learning. Journal of Nursing Education, 50(8), 471-5. doi:10.3928/01484834-20110531-01

Meechan, R., Mason, V., \& Catling, J. (2011). The impact of an integrated pharmacology and medicines management curriculum for undergraduate adult nursing students on the acquisition of applied drug/pharmacology knowledge. Nurse Education Today, 31(4), 383-389. doi:10.1016/j.nedt.2010.07.011

Middleton, D. A. (2008). A standardized nursing mathematics competency program. Nurse Educator, 33(3), 122-124. doi:10.1097/01.NNE.0000312184.43766.57

Noss, R., Hoyles, C., \& Pozzi, S. (2002). Abstraction in expertise: A study of nurses' conceptions of concentration. Journal for Research in Mathematics Education, 33(3), 204-229.

Pearson, Y. (forthcoming). The evidence-based approach to nursing practice: Examining barriers to implementation in an Ontario hospital. (Unpublished Master of Education thesis). Nipissing University, North Bay, ON.

Royse, M. A., \& Newton, S. E. (2007). How GAMING is used as an innovative strategy FOR nursing education. Nursing Education Perspectives, 28(5), 263-267. http://dx.doi.org/10.1043/1536-5026(2007)28[263:HGIUAA]2.0.CO;2

Rush, K. L. (2008). Connecting practice to evidence using laptop computers in the classroom. CIN: Computers, Informatics, Nursing, 26(4), 190-198.

Schutt, M., \& Hightower, B. (2009). Enhancing RN-to-BSN students' information literacy skills through the use of instructional technology. Journal of Nursing Education, 48(2), 101105. doi:10.3928/01484834-20090201-11

Serembus, J. F., Wolf, Z. R., \& Youngblood, N. (2001). Consequences of fatal medication errors for health care providers: A secondary analysis study. MEDSURG Nursing, 10(4), 193201.

Skiba, D. J. (2009). Nursing education 2.0: A second look at second life. Nursing Education Perspectives, 30(2), 129-131. http://dx.doi.org/10.1043/1536-5026-030.001.0048

Sorensen, H., \& Yankech, L. R. (2008). Precepting in the fast lane: Improving critical thinking in new graduate nurses. Journal of Continuing Education in Nursing, 39(5), 208-216. doi:10.3928/00220124-20080501-07

Spencer, J. A. (2012). Integrating informatics in undergraduate nursing curricula: Using the QSEN framework as a guide. Journal of Nursing Education, 51(12), 697-701. doi:10.3928/01484834-20121011-01 
Stetler, C. (2003). Role of the organization in translating research into evidence-based practice. Outcomes Management, 7(3), 97-103.

Stetler, C., McQueen, L., Demakis, J., \& Mittman, B. (2008). An organizational framework and strategic implementation for system-level change to enhance research-based practice: QUERI Series. Implementation Science, 3(30). doi: 10.1186/1748-5908-3-30

Strickland, K., Gray, C., \& Hill, G. (2012). The use of podcasts to enhance research-teaching linkages in undergraduate nursing students. Nurse Education in Practice, 12(4), 210-214. doi:10.1016/i.neDr.2012.01.006

Sulosaari, V., Suhonen, R., \& Leino-Kilpi, H. (2011). An integrative review of the literature on registered nurses' medication competence. Journal of Clinical Nursing, 20(3), 464-478. doi:10.1111/j.1365-2702.2010.03228.x

Tanaka, R., Catalan, V., Zemiack, J., Pedro, E., Petersen, A., \& Silveira, D. (2010). Digital learning objects: An assessment of a tool for the practice of nursing education. Acta Paulista De Enfermagem, 23(5), 603-607. http://dx.doi.org/10.1590/S010321002010000500003

Vagliardo, J. J. (2008). Mathematics and nursing: Students' conceptual understanding of mathematics for nursing. (Doctoral dissertation). Retrieved from ProQuest Dissertations and Theses database. (UMI No. AAI3320156)

Wright, K. (2009). The assessment and development of drug calculation skills in nurse education: A critical debate. Nurse Education Today, 29(5), 544-548. http://dx.doi.org/10.1016/j.nedt.2008.08.019

Wright, K. (2012). Student nurses' perceptions of how they learn drug calculation skills. Nurse Education Today, 32(6), 721-726. doi:10.1016/j.nedt.2011.09.014

Zurmehly, J. (2010). Personal digital assistants (PDAs): Review and evaluation. Nursing Education Perspectives, 31(3), 179-182. http://dx.doi.org/10.1043/1536-5026-31.3.179 